\title{
PLZF is a regulator of homeostatic and cytokine-induced myeloid development
}

\author{
Sergei Doulatov, ${ }^{1,2}$ Faiyaz Notta, ${ }^{1,2,5}$ Kim L. Rice, ${ }^{3,5}$ Louise Howell, $^{4}$ Arthur Zelent, ${ }^{4}$ \\ Jonathan D. Licht, ${ }^{3}$ and John E. Dick ${ }^{1,2,6}$ \\ ${ }^{1}$ Division of Cell and Molecular Biology, University Health Network, Toronto, Ontario M5G 1L7, Canada; ${ }^{2}$ Department \\ of Molecular Genetics, University of Toronto, Toronto, Ontario M5G 1L7, Canada; ${ }^{3}$ Division of Hematology/Oncology, \\ Robert H. Lurie Comprehensive Cancer Center, Northwestern University Feinberg School of Medicine, Chicago, Illinois \\ 60611, USA; ${ }^{4}$ Section of Haemato-Oncology, Institute of Cancer Research, Belmont, Sutton, Surrey SM2 5NG, United Kingdom
}

\begin{abstract}
A major question in hematopoiesis is how the system maintains long-term homeostasis whereby the generation of large numbers of differentiated cells is balanced with the requirement for maintenance of progenitor pools, while remaining sufficiently flexible to respond to periods of perturbed cellular output during infection or stress. We focused on the development of the myeloid lineage and present evidence that promyelocytic leukemia zinc finger (PLZF) provides a novel function that is critical for both normal and stress-induced myelopoiesis. During homeostasis, PLZF restricts proliferation and differentiation of human cord blood-derived myeloid progenitors to maintain a balance between the progenitor and mature cell compartments. Analysis of PLZF promoter-binding sites revealed that it represses transcription factors involved in normal myeloid differentiation, including GFI-1, C/EBP $\alpha$, and LEF-1, and induces negative regulators DUSP6 and ID2. Loss of ID2 relieves PLZF-mediated repression of differentiation identifying it as a functional target of PLZF in myelopoiesis. Furthermore, induction of ERK1/2 by myeloid cytokines, reflective of a stress response, leads to nuclear export and inactivation of PLZF, which augments mature cell production. Thus, negative regulators of differentiation can serve to maintain developmental systems in a primed state, so that their inactivation by extrinsic signals can induce proliferation and differentiation to rapidly satisfy increased demand for mature cells.
\end{abstract}

[Keywords: Myeloid differentiation; human hematopoiesis; lineage determination; transcription factors]

Supplemental material is available at http://www.genesdev.org.

Received February 4, 2009; revised version accepted July 21, 2009.

Myeloid cells, including macrophages and neutrophils, are an intrinsic component of the innate immune system. Mature myeloid cells in the periphery rapidly turn over and are replenished by differentiation from myeloid progenitors in the bone marrow. This process is orchestrated by a complex interplay of transcription factors and cytokine signals that govern an ordered activation and repression of lineage-specific genes. Networks of transcription factors that regulate myeloid development have been extensively studied and modeled (Laiosa et al. 2006; Laslo et al. 2006). Macrophage and neutrophil specification require master regulators PU.1 and $\mathrm{C} / \mathrm{EBP} \alpha$, which control more "specialized" downstream transcription factors, including GFI1 and EGR2 (Laslo et al. 2006). Since blood production is enormous $\left(\sim 10^{12}\right.$ cells per day in human) and continues for a lifetime, homeostatic mechanisms must be in place to permit ongoing differentiation

\footnotetext{
${ }^{5}$ These authors contributed equally to this work.

${ }^{6}$ Corresponding author.

E-MAIL jdick@uhnres.utoronto.ca; FAX (416) 581-7471.

Article is online at http://www.genesdev.org/cgi/doi/10.1101/gad.1788109.
}

without depletion of progenitor pools. Although the molecular mechanisms that govern lineage determination are well understood, how myeloid transcription factors maintain the balance between the progenitor and mature cell compartments is less clear. Proper regulation ensures an adequate supply of mature cells, while leukemogenesis and other myeloid malignancies are often driven by inappropriate activity of these transcription factors (Rosenbauer and Tenen 2007). Thus, identification and characterization of novel regulators of myelopoiesis is of interest from the standpoint of both normal and malignant hematopoiesis.

Besides maintaining homeostasis, developmental systems must remain flexible to respond to emergent events. During immune activation, high levels of secreted cytokines stimulate myeloid-mediated innate immunity (Cannistra and Griffin 1988; Oster et al. 1988). Of these, G-CSF, GM-CSF, and IL-3 were initially isolated as colony-stimulating factors owing to their potential to stimulate proliferation, survival, and differentiation of hematopoietic progenitors (Donahue et al. 1988; Lieschke et al. 1994). Following binding to their cognate receptors, 
cytokines activate parallel JAK/STAT, MAPK, and PI3K signal transduction pathways, which modify expression and activation of downstream transcription factor effectors (Barreda et al. 2004). For instance, STAT3 and $\mathrm{C} / \mathrm{EBP} \beta$ are dispensable for normal, but are required for cytokine-induced, myelopoiesis (Hirai et al. 2006; Panoupolos 2006). Still, the mechanisms by which stress-induced cytokines interact with the network of myeloid transcription factors remain largely unexplored.

Kruppel-like transcription factor promyelocytic leukemia zinc finger (PLZF) is expressed in CD $34^{+}$hematopoietic progenitors, but not mature cells, suggesting it may play a role in lineage determination (Reid et al. 1995). PLZF is a negative regulator of cell division in embryogenesis and controls segment patterning through repression of $H O X$ and $B M P$ expression (Barna et al. 2000). In the adult, PLZF augments self-renewal of spermatogonial stem cells and its deletion results in sterility (Buaas et al. 2004; Costoya et al. 2004). In hematopoiesis, PLZF has been implicated in the development of megakaryocytic (Labbaye et al. 2008) and NKT cell lineages (Kovalovsky et al. 2008; Savage et al. 2008). PLZF was identified as a chromosomal fusion partner with RAR $\alpha$ in promyelocytic leukemia, a disease marked by an accumulation of undifferentiated myeloid blasts (Chen et al. 1993). Consistent with a role in myelopoiesis, enforced expression of PLZF in myeloid cell lines resulted in inhibition of proliferation and differentiation (Shaknovich et al. 1998; Ward et al. 2001; McConnell et al. 2003). In these distinct systems, PLZF is a sequence-specific transcriptional repressor that recruits nuclear corepressors to establish silenced chromatin structure at target promoters (Hong et al. 1997; Barna et al. 2002). Thus, PLZF can maintain long-term epigenetic repression of target genes, which is an integral aspect of cellular "memory" in fate determination and differentiation (Fisher 2002).

Most studies of mammalian hematopoiesis have used the mouse as a model organism. The improvement of gene transfer methods and "humanized" xenograft mouse models now provide the possibility of carrying out comparable studies with primary human cells, which may be a more relevant model for many aspects of normal human biology and disease. Using this approach, we identify a previously unrecognized mechanism of homeostatic regulation, whereby the balance between maintenance and commitment myeloid progenitors is controlled by cytokine-mediated inhibition of a differentiationsuppressing transcription factor, PLZF.

\section{Results \\ PLZF is expressed in human hematopoietic stem cells (HSCs) and progenitors}

PLZF is expressed in human CD $34^{+}$hematopoietic progenitors and its expression declines in differentiated cells (Reid et al. 1995). To refine this analysis, PLZF transcript expression was assessed by quantitative real-time PCR (qPCR) in HSC-enriched $\left(\mathrm{CD} 34^{+} \mathrm{CD} 38^{-}\right)$, myeloid progenitor $\left(\mathrm{CD} 34^{+} \mathrm{CD} 38^{+} \mathrm{CD} 71^{-}\right)$, and erythroid progenitor $\left(\mathrm{CD} 34^{+} \mathrm{CD} 38^{+} \mathrm{CD} 71^{+}\right)$fractions, isolated from lineagedepleted $\left(\operatorname{Lin}^{-}\right)$umbilical cord blood (CB). Comparable levels of PLZF expression were detected in all three fractions; however, its expression rapidly declined in progenitors isolated from culture under conditions that promote differentiation (Fig. 1A). This pattern of expression suggests that PLZF may play a role in differentiation of hematopoietic progenitors.

\section{PLZF restricts myeloid proliferation and differentiation in vitro}

To characterize the requirement for PLZF in human hematopoiesis, we designed lentiviral and retroviral vectors to enforce or silence expression (Fig. 1B). Transduction of $293 \mathrm{~T}$ cells with retroviral MPG-PLZF or
A

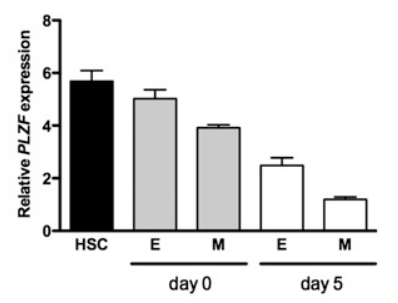

C

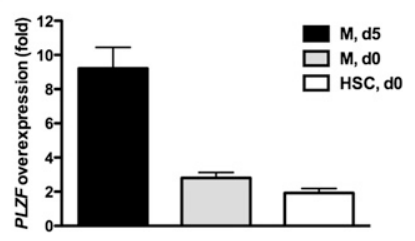

B

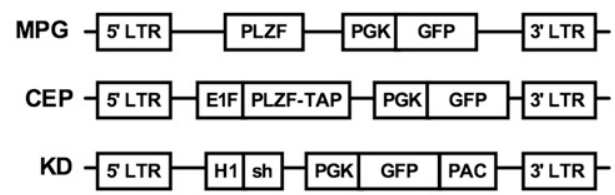

D

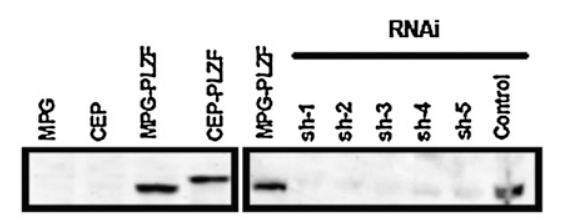

Figure 1. PLZF expression and viral vector design. (A) Expression of PLZF mRNA in human hematopoietic subsets, before and after culture, was quantified by qPCR. Hematopoietic subsets were isolated by FACS-sorting from fresh $\mathrm{Lin}^{-} \mathrm{CB}$ (day 0) or after $5 \mathrm{~d}$ in serum-free culture (day 5) based on the following phenotypes: HSCs, CD $34^{+} \mathrm{CD}^{-} 8^{-}$, erythroid progenitors $(\mathrm{E}), \mathrm{CD} 34^{+} \mathrm{CD} 38^{+} \mathrm{CD} 71^{+}$, myeloid progenitors $(\mathrm{M})$, and $\mathrm{CD} 34^{+} \mathrm{CD} 38^{+}$ $\mathrm{CD} 1^{-}$. (B) Schematic representation of viral vectors used to overexpress (MPG, retroviral; CEP, lentiviral) or silence human $P L Z F$ (shPLZF). (C) Fold overexpression of PLZF in myeloid progenitors transduced with MPGPLZF and cultured for $5 \mathrm{~d}$, compared with same-day control cells $(\mathrm{M}, \mathrm{d} 5)$, or freshly sorted myeloid progenitors $(\mathrm{M}, \mathrm{d} 0)$ or HSCs (HSC, d0) from the same CB. (D, left panel) Western blot analysis of total protein extracts from $293 \mathrm{~T}$ cells transduced with control or MPG-PLZF viruses. (Right panel) Silencing vectors (shPLZF1-3) were transduced into 293T cells stably expressing PLZF. Equal total protein was loaded in all lanes and the blots were probed with an anti-PLZF antibody. 
Doulatov et al.

lentiviral TAP-tagged CEP-PLZF vectors yielded protein of expected size (Fig. 1D). Transcript abundance in PLZF-transduced (termed PLZF ${ }^{\mathrm{OX}}$ ) $\mathrm{CD}^{+} 4^{+}$cells was $2.8 \pm$ 0.3 -fold and $1.9 \pm 0.3$-fold compared with $\mathrm{Lin}^{-} \mathrm{CB}$ myeloid progenitors or HSCs, respectively (Fig. 1C). Finally, infection of PLZF ${ }^{\text {OX }} 293$ cells with short hairpin PLZF knockdown viruses (sh-PLZF) effectively abolished protein expression (Fig. 1D; see also Supplemental Fig. S1).

Since PLZF expression is down-regulated rapidly during differentiation, we tested the effect of enforcing its constitutive expression in cultured primary human progenitors. Lin $^{-} \mathrm{CB}$ cells were infected with control or
MPG-PLZF vectors and $\mathrm{GFP}^{+} \mathrm{CD} 34^{+}$progenitors (which contain myeloid and erythroid progenitors, but negligible HSCs) were assayed in liquid cultures and colony assays. After $3 \mathrm{wk}, \mathrm{PLZF}^{\mathrm{OX}}$ progenitors displayed 4.0-fold and 5.2-fold lower proliferative capacity in serum-free and serum-supplemented cultures, respectively (Fig. 2A). Annexin $\mathrm{V}$ staining revealed no significant differences in the proportion of apoptotic cells in these cultures (Fig. 2B). Notably, BrdU incorporation assays demonstrated that the decrease in proliferation was directly attributable to reduced entry into S phase (Fig. 2C). These observations are consistent with the proposed tumor suppressor function of PLZF (McConnell et al. 2003).
Figure 2. PLZF restricts myeloid proliferation and differentiation of human progenitors in vitro. $(A)$ Effect of PLZF on progenitor proliferation. Growth of CD34 ${ }^{+}$ progenitors transduced with MPG (control) or MPGPLZF (PLZF ${ }^{\mathrm{OX}}$ ) vectors in serum-free and serum-supplemented cultures quantified by total cell counting. $(B)$ Effect of PLZF on apoptosis. Proportion of annexin $\mathrm{V}^{+}$ $\left(7 \mathrm{AAD}^{-}\right)$apoptotic cells after $7 \mathrm{~d}$ in serum-supplemented cultures initiated with control or PLZF ${ }^{\mathrm{OX}}$ CD $34^{+}$cells; the difference between groups is not significant. (C) Effect of PLZF on cell cycle kinetics. BrdU incorporation of control and $\mathrm{PLZF}^{\mathrm{OX}} \mathrm{CD} 34^{+}$cells cultured for $7 \mathrm{~d}$ in serum-free conditions; representative flow cytometric profiles (left panel) and the proportion of cells in $G_{0} / G_{1}, S$, and $G_{2} / M$ phases of the cell cycle (right panel) are shown. (D) Effect of PLZF on myeloid differentiation. Proportion of nonmyeloid $/ \mathrm{CD} 15^{-}$ $\mathrm{CD}_{14}^{-} \mathrm{CD}^{-} \mathrm{b}^{-}$) cells in serum-free cultures initiated with control or $\mathrm{PLZF}^{\mathrm{OX}} \mathrm{CD}^{+} 4^{+}$cells. $(E)$ Production of mature lineage-positive myeloid cells in serum-free cultures initiated with sorted control or PLZF ${ }^{\mathrm{OX}}$ CD34 ${ }^{+}$cells. $(F)$ Effect of PLZF on clonogenic progenitors. Colony-forming capacity (colonies counted as proportion of input; percentage of CFU) of freshly sorted control or $\mathrm{PLZF}^{\mathrm{OX}} \mathrm{CD}^{+} 4^{+}$cells. (BFU-E) Erythroid blast-forming units; (CFU-G/M) granulocyte or monocyte colony-forming units; (CFU cells) total myeloid cells $\times 10^{5}$ in a CFU-G/M assay. All data are expressed as mean \pm SEM of three independent experiments $(\mathrm{CB}$ samples), except $F$, which has four experiments. $\left(^{\star}\right) P<$ $\left.0.05 ;{ }^{\star \star}\right) P<0.005$.
A
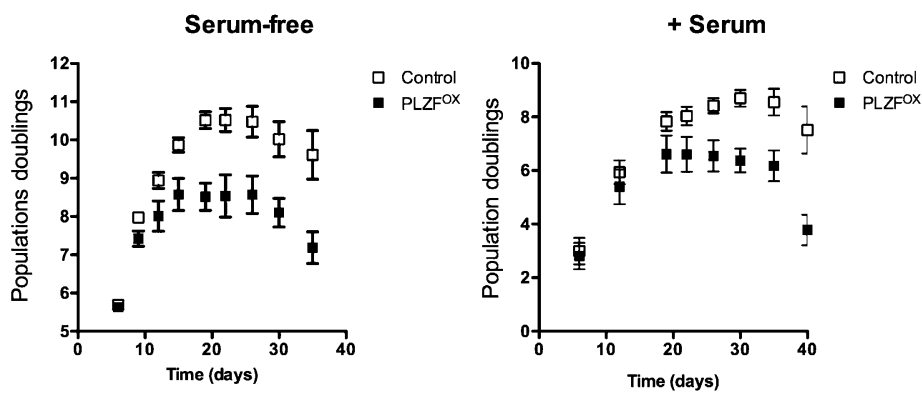

B
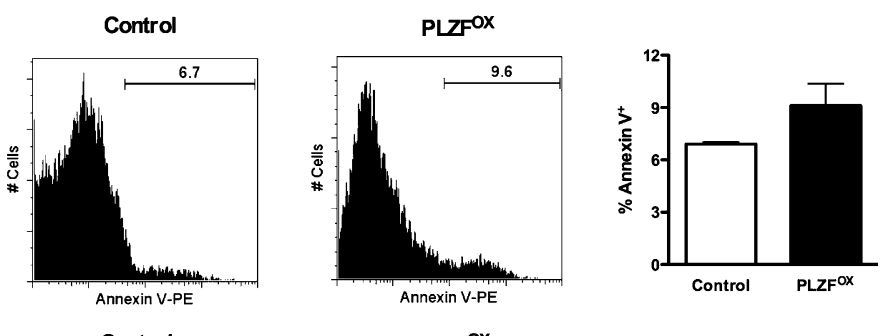

C

Control
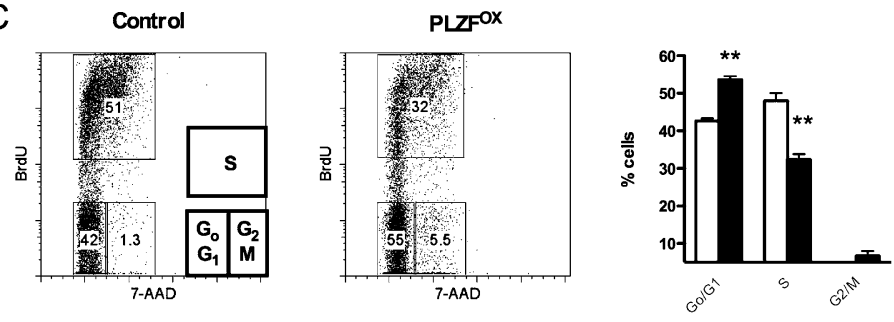

D

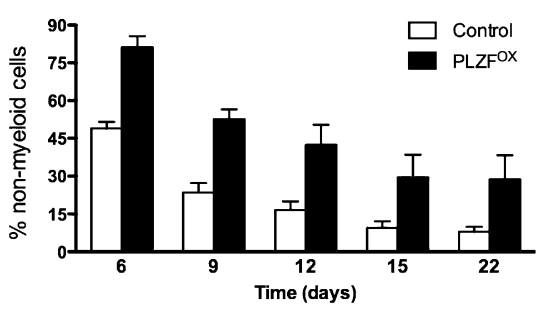

E
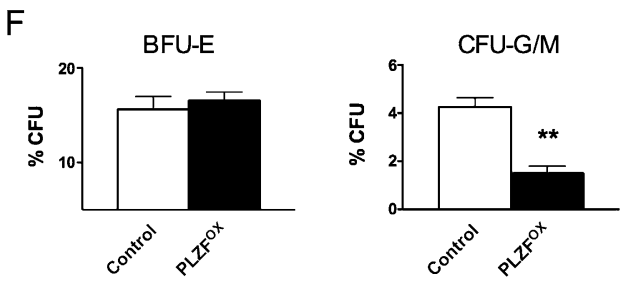
To assess the effect of constitutive expression of PLZF on differentiation, we analyzed the frequency of cells that had acquired CD14, CD15, and CD11b mature myeloid lineage markers. As control $\mathrm{Lin}^{-}$cells differentiated, 92.1 $\pm 2.0 \%$ of them acquired these markers after $3 \mathrm{wk}$ in culture. In contrast, $29 \pm 9.6 \%$ of $\mathrm{PLZF}^{\mathrm{OX}}$ cells did not express the markers of differentiation at this time point (Fig. 2D). Thus, combined with the 4.0-fold reduction of proliferation, PLZF decreased total output of mature myeloid cells by 12.1-fold over 3 wk (Fig. 2E).

Myeloid development can also be functionally tested using colony assays, which measure the frequency and growth potential of clonogenic progenitors. Freshly sorted (day 0) $\mathrm{CD}^{+} 4^{+} \mathrm{PLZF}^{\mathrm{OX}}$ progenitors formed an equal proportion of erythroid colonies (Fig. 2F, BFU-E) as controls, but gave rise to $2.7 \pm 0.2$-fold fewer granulocyte or macrophage colonies (Fig. 2F, CFU-G/M). Since an equal number of transduced progenitors were seeded, these results represent the effect of PLZF on the clonal growth potential of myeloid progenitors. This conclusion is also supported by the equivalent reduction of the total cell output from PLZF ${ }^{\mathrm{OX}}$ progenitors in colony assays (Fig. 2F, CFU cells). Collectively, these findings indicate that PLZF inhibits myeloid proliferation and differentiation in vitro.

Expression of $P L Z F$ is quickly lost in culture, as primitive cells differentiate (see Fig. 1B), so further reduction of PLZF levels by knockdown is expected to have no phenotypic consequences. Indeed, three independent sh-PLZF vectors had no effect on the growth of myeloid progenitors when PLZF was not expressed (Supplemental Fig. S1, control) indicating that these hairpins do not have off-target effects that alter cell growth and differentiation. However, all three shRNA vectors partially rescue (72\%$74 \%$ ) colony growth in the context of ectopic PLZF expression providing a functional measure of knockdown efficiency in primary progenitors (Supplemental Fig. S1, $\mathrm{PLZF}^{\mathrm{OX}}$ ). These data demonstrate that sh-PLZF lentiviruses specifically target PLZF and provide a functional rescue of its effects in myeloid progenitors.

\section{PLZF restricts human myelopoiesis in vivo}

During culture, progenitors are not maintained due to rapid differentiation, making it impossible to study the process of human hematopoiesis over time. In contrast, in vivo xenotransplantion of human cells into immunodeficient mice does allow for maintenance of progenitors, so we used this system to more fully investigate the role of PLZF in human hematopoiesis. Lin ${ }^{-} \mathrm{CB}$ cells were transduced with PLZF overexpression and knockdown vectors containing a GFP reporter. The level of gene transfer into $\mathrm{CD} 4^{+} \mathrm{CD} 133^{+}$HSCs ranged from $5 \%$ to $10 \%$ (Fig. 3A, indicated by broken lines), and NOD/SCID mice were transplanted with a mixture of transduced and nontransduced $\left(\mathrm{GFP}^{-}\right)$cells. Silencing of PLZF (termed PLZF ${ }^{\mathrm{KD}}$ ) using two independent sh-PLZF vectors enhanced the capacity of GFP-marked hematopoietic cells to contribute to the repopulation of the NOD/SCID bone marrow with human bone marrow cells (termed BMCs). There was a $2.5 \pm 0.4$-fold increased proportion of $\mathrm{GFP}^{+} \mathrm{PLZF}^{\mathrm{KD}}$
BMCs in the human $\mathrm{CD}_{4} 5^{+}$graft at 8 wk post-transplant compared with the proportion of $\mathrm{GFP}^{+}$cells prior to transplantation (three experiments, $P<0.02$ for all) (Fig. 3A, Knockdown, cf. solid and broken lines). These data suggest that $\mathrm{PLZF}^{\mathrm{KD}}$ cells have a modest competitive advantage over their nontransduced counterparts. As expected, the proportion of $\mathrm{GFP}^{+}$cells after transplantation of empty vector-transduced or irrelevant red fluorescent protein (shRFP) hairpin-transduced cells was unchanged compared with input transduction levels, indicating that these cells had no proliferative advantage over $\mathrm{GFP}^{-}$cells (Fig. 3A). In contrast, the proportion of $\mathrm{GFP}^{+} \mathrm{PLZF}^{\mathrm{OX}}$ BMCs was decreased in the CD $45^{+}$graft by $3.9 \pm 0.1$-fold (three experiments, $P<0.002$ ) (Fig. 3A, Overexpression).

To determine if the increased mature cell production was specific to a particular lineage, we assessed lineage distribution within the $\mathrm{GFP}^{+}$graft. $\mathrm{PLZF}^{\mathrm{KD}}$ BMCs were composed of $77.5 \pm 1.6 \%$ (control $85.9 \pm 1.6 \%$ ) SSC S $^{\text {lo }}$ $\mathrm{CD}^{-}$B-lymphocytes, $12.3 \pm 1.3 \%$ (control $5.2 \pm 0.3 \%$ ) SSC $^{\text {hi }} \mathrm{CD} 3^{\text {lo }}$ granulocytes, and $9.2 \pm 1.0 \%$ (control $7.8 \pm$ $1.5 \%$ ) SSC $^{\text {lo }} \mathrm{CD} 33^{\text {hi }}$ monocytes (five experiments; granulocytes, $P<0.001$ ) (Fig. 3B). There were not enough cells of other lineages for flow analysis. Taking into account the overall 2.5-fold expansion of PLZF ${ }^{\mathrm{KD}}$ BMCs, knockdown of PLZF increased the absolute number of granulocytes by $6.0 \pm 1.7$-fold, compared with controls (Fig. 3C). Furthermore, increased granulocyte numbers were largely due to augmented production of neutrophils expressing maturation markers CD11b and CD16 (Fig. 3D). These observations suggest that PLZF decreases proliferation and/or differentiation of myeloid cells in vivo.

\section{PLZF regulates the balance between progenitor and mature compartments}

To determine if the increased contribution of $\mathrm{PLZF}^{\mathrm{KD}}$ cells to the myeloid graft reflects an expansion of immature progenitors, marrow from mice transduced with control or PLZF-bearing viruses was pooled and depleted of murine and mature human cells to enable more precise flow cytometric analysis of the immature engrafted populations (see the Materials and Methods). As expected for empty vector and shRFP controls, the proportion of $\mathrm{GFP}^{+}$cells in unfractionated $\mathrm{CD} 45^{+}$bone marrow and $\mathrm{Lin}^{-} \mathrm{CD}^{+} 4^{+}$fractions was equivalent (Fig. 4A, Control). Surprisingly, knockdown of PLZF decreased the contribution of $\mathrm{GFP}^{+}$cells to the progenitor compartment by $2.6 \pm 0.1$-fold, compared with total BMCs (Fig. 4A [Knockdown], B). Conversely, the proportion of $\mathrm{GFP}^{+}$ $\mathrm{PLZF}^{\mathrm{OX}}$ cells in the primitive $\mathrm{Lin}^{-} \mathrm{CD} 34^{+}$fraction was increased by $5.4 \pm 0.5$-fold (Fig. 4A [Overexpression], B). Thus, while negatively regulating the mature myeloid compartment, PLZF also expanded the pool of undifferentiated progenitors.

The number of progenitors in vivo was determined independently using colony assays. PLZF ${ }^{\mathrm{OX}}$ granulocyte or monocyte colony-forming units (CFU-G/M) were overrepresented by 15.7 -fold, whereas $\mathrm{PLZF}^{\mathrm{KD}}$ progenitors were depleted by 4.6-fold (Fig. 4B), providing an independent correlation with the phenotypic data. In 
Figure 3. PLZF negatively regulates myeloid development in vivo as assessed in the NOD/SCID xenotransplant system. (A) Effect of PLZF on CD45 human cell engraftment. Proportion of $\mathrm{GFP}^{+}$BMCs in individual mice each denoted with a symbol at 8 wk post-transplant (mean marked as solid lines) compared with mean GFP positivity of input HSCs prior to transplantation (broken lines). Lin $^{-} \mathrm{CB}$ cells were transduced with control (clear triangles), PLZF knockdown $\left(\mathrm{PLZF}^{\mathrm{KD}}\right)$, or CEP-PLZF (PLZF ${ }^{\mathrm{OX}}$ ) vectors (black triangles) and transplanted into NOD/SCID mice. The level of transduction in three independent experiments ranged from $5 \%$ to $12 \%$; as a result, mice were transplanted with a mixture of transduced and nontransduced cells. Thus, equivalent means in the values of the pretransplant and post-transplant percentage of GFP in each experiment indicates a lack of competitive advantage of $\mathrm{GFP}^{+}$cells relative to nontransduced cells, while increased or decreased percentage of $\mathrm{GFP}^{+}$indicates competitive advantage or disadvantage, respectively, in vivo. (B) Frequency of human myeloid BMCs in mice transplanted with $\mathrm{PLZF}^{\mathrm{KD}}$ cells (right) and a representative flow analysis (left). The frequency of granulocytes was calculated as the proportion of SSC ${ }^{\text {hi }} \mathrm{CD} 33^{\text {lo }}$ cells within the $\mathrm{GFP}^{+} \mathrm{CD}^{+} 5^{+}$graft and monocytes as $\mathrm{SSC}^{\text {lo }}$ CD $33^{\text {hi }}$ cells within the $\mathrm{GFP}^{+} \mathrm{CD} 45^{+}$graft; the remaining cells were $\mathrm{SSC}^{\text {lo }} \mathrm{CD} 33^{-}$lymphocytes. To obtain enough cells for accurate flow cytometric analysis, bone marrow was pooled from four to eight mice. Data are expressed as mean \pm SEM of five independent experiments. $\left(^{\star \star}\right) P<0.01$. (C) Expansion of the absolute number of human granulocytes, monocytes, and lymphoid cells in mice transplanted with PLZF ${ }^{\mathrm{KD}}$ cells normalized to controls. The absolute number was calculated by multiplying the frequency of each cell type by the number of $\mathrm{GFP}^{+}$ $\mathrm{CD} 5^{+}$cells in both femurs, tibiae, and pelvis. Data are expressed as mean \pm SEM of five independent experiments. $\left({ }^{\star}\right) P<0.02 .(D)$ Representative analysis of the proportion of $\mathrm{CD} 11 \mathrm{~b}^{+} \mathrm{CD} 16^{+}$human neutrophils in the $\mathrm{GFP}^{+}$fraction of mice engrafted with Lin ${ }^{-} \mathrm{CB}$ cells transduced with control, $\mathrm{PLZF}^{\mathrm{KD}}$, or PLZF ${ }^{\mathrm{OX}}$ viruses. To obtain enough cells for accurate flow cytometric analysis, bone marrow was pooled from four to eight mice.

contrast to our in vitro experiments, the number of seeded progenitors was not the same between control and PLZF mice. However, since PLZF expanded Lin $^{-}$ $\mathrm{CD} 4^{+}$cells, we infer that the increase in CFU-G/M in vivo is due to an increased number of progenitor cells, rather than their clonogenic potential.

Taken together, these results demonstrate that rather than conferring a general proliferative advantage to human cells in vivo, PLZF specifically regulates the balance between the progenitor and mature compartments. Higher levels of PLZF maintain undifferentiated progenitors and curb their mature output, while silencing causes depletion of progenitors due to an increased rate of proliferation and differentiation.

\section{Cytokines modulate PLZF repression of myeloid development}

Since our data suggest that PLZF normally functions to negatively regulate entry of progenitors into terminal differentiation, we sought to determine the involvement of PLZF in myelopoiesis stimulated by stress-induced cytokines. Overexpression of PLZF in the absence of cytokine exposure reduced the growth potential of clonogenic progenitors (see Fig. 2F). However, when PLZF ${ }^{\mathrm{OX}}$ progenitors were seeded in the presence of IL-3, myeloid colony-forming potential was restored to nearly normal levels, suggesting that IL-3 signaling can alleviate the defect in growth and differentiation (Fig. 5A). As expected, IL-3 also improved the clonogenic potential of control cells, but to a much lesser extent (Fig. 5A). As colony assays are performed in the presence of several cytokines (see the Materials and Methods), we sought to examine the effect of individual cytokines. CD $34^{+}$ $\mathrm{CD} 71^{-}$myeloid progenitors were stimulated with a select cytokine for $24 \mathrm{~h}$ in serum-free medium supplemented with BSA, insulin, and transferrin (SFM + BIT) to maintain cellular viability and seeded in methylcellulose. The potential of PLZF to repress colony-forming capacity was significantly alleviated by stimulation with IL-3, GM-CSF, or G-CSF (all $P<0.01$ ), all of which have been implicated as key mediators of stress-induced 
A

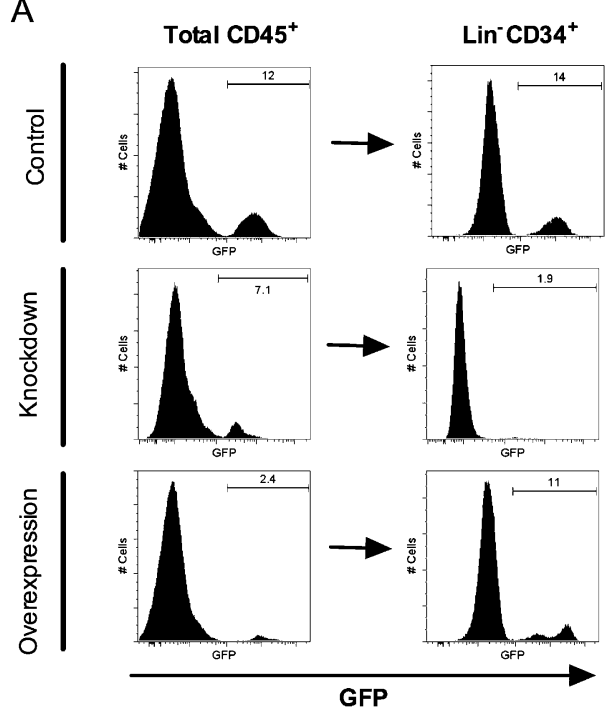

B

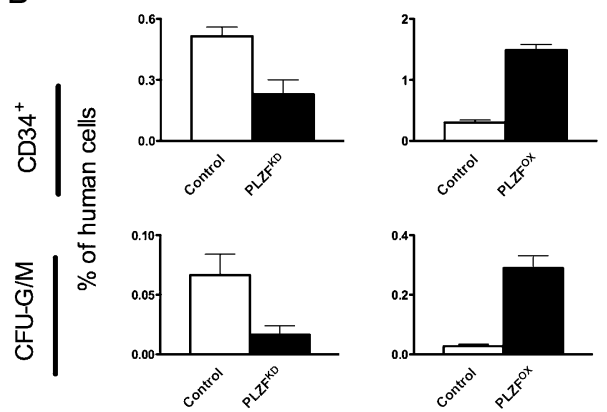

Figure 4. PLZF expands the human progenitor compartment in vivo. (A) Proportion of $\mathrm{GFP}^{+}$cells within the total human $\mathrm{CD}^{+} 5^{+}$ graft in the bone marrow (left) compared with $\mathrm{Lin}^{-} \mathrm{CD} 34^{+}$ progenitor fraction (right) in a representative experiment $8 \mathrm{wk}$ post-transplant. Bone marrow was pooled from four to eight mice, depleted of murine and mature human cells, and analyzed for GFP and CD34 expression by flow cytometry before and after lineage depletion. Equal percentage of GFP indicates equal contribution of transduced cells to mature and progenitor compartments, while increased or decreased proportion reflects expansion or depletion of progenitors relative to total cells. (B) Proportion of $\mathrm{Lin}^{-} \mathrm{CD} 34^{+}$progenitors and myeloid colonyforming units (CFU-G/M) within the total $\mathrm{CD}^{4} 5^{+}$graft in mice transplanted with $\mathrm{PLZF}^{\mathrm{KD}}$ or $\mathrm{PLZF}^{\mathrm{OX}}$ cells. Data are expressed as mean \pm SEM of two independent experiments, each with $\mathrm{Lin}^{-}$cells isolated from four to eight engrafted mice.

myelopoiesis (Fig. 5B; Hirai et al. 2006). However, IL-6 or all-trans retinoic acid (ATRA), which have distinct biological roles, did not promote myelopoiesis in the presence of PLZF (Fig. 5B). These results suggest that stress-induced cytokines can act by interfering with the capacity of PLZF to inhibit proliferation and differentiation.

To probe the interaction of PLZF and cytokines on the molecular level, we profiled the expression of key indicators of myeloid differentiation in culture by qPCR. Both
c-MYC (MYC) and GATA-2 transcription factors are normally expressed in myeloid progenitors and expression declines with differentiation (Johansen et al. 2001; Kobayashi-Osaki et al. 2005). Consistent with their impaired differentiation, PLZF ${ }^{\mathrm{OX}}$ myeloid progenitors had higher levels of MYC and GATA-2 transcripts; however, normal levels were restored if the transduced cells were cultured with IL-3 (Fig. 5C). The C/EBP family of transcription factors (C/EBPs) are expressed in an ordered fashion during normal neutrophil differentiation (Bjerregaard et al. 2003). Transcript expression of C/EBPs in $\mathrm{CB}$ cells was blocked by PLZF (all $P<0.05$, except $C E B P A)$; however, normal levels were restored in the presence of IL-3 (Fig. 5D). Notably, the degree of repression by PLZF correlated with their normal order of expression during differentiation $(\mathrm{C} / \mathrm{EBP} \alpha<\varepsilon<\delta<\beta)$, such that $\mathrm{C} / \mathrm{EBPs}$ expressed in more mature cells were more strongly repressed (Bjerregaard et al. 2003). The ordered repression of these transcription factors suggests that PLZF establishes a molecular state that impairs differentiation, while the addition of cytokines restores a normal pattern of myeloid development.

To investigate the pathway(s) responsible for cytokinemediated inhibition of PLZF, sorted CD $34^{+} \mathrm{CD} 71^{-}$myeloid progenitors were cultured in SFM + BIT, treated with IL-3 in the presence of specific protein kinase inhibitors for $24 \mathrm{~h}$, and seeded in methylcellulose. Control and PLZF ${ }^{\mathrm{OX}}$ progenitors treated with p38 MAPK (SB203580 and SB202190), JNK (SP600125), or PI-3K (LY294002) inhibitors showed a similar response to IL-3 stimulation (Fig. 5E). Treatment with JAK inhibitor AG490 drastically reduced colony formation of both control and PLZF ${ }^{\mathrm{OX}}$ cells, but there was no difference in their response to IL-3. Only specific MEK inhibitors PD98059 and U0126, which impair downstream ERK1/2 (ERK) activation, restored PLZF-mediated repression of myeloid colony formation in the presence of IL-3 (both $P<0.01$ ) (Fig. 5E). Thus, IL-3 interferes with PLZF repression by activating ERK signal transduction.

In CD $34^{+}$progenitors and myeloid cell lines, PLZF is localized to distinct nuclear domains, while its loss-offunction mutants exhibit aberrant localization (Reid et al. 1995; Guidez et al. 2005). To examine the effect of cytokines on native cellular localization of PLZF, nontransduced $\mathrm{CD} 34^{+} \mathrm{CD} 71^{-}$myeloid progenitors were cultured in SFM + BIT with or without IL-3 for $24 \mathrm{~h}$, and distribution of PLZF was visualized by immunofluorescence microscopy. In the absence of cytokines, most cells expressed PLZF protein, which was found in the nucleus and the cytoplasm (Fig. 5F, -IL-3). Stimulation with IL-3 resulted in a redistribution of nuclear PLZF to the cytoplasm (Fig. 5F, +IL-3), and this effect was enhanced by cotreatment with other differentiationinducing agents, such as ATRA (Fig. 5F, +IL-3 +ATRA). However, nuclear localization was completely restored upon cotreatment with the specific ERK inhibitor PD98059 (Fig. 5F, +IL-3 +iMEK). These results suggest that cytokines mediate inactivation of PLZF by triggering its export from the nucleus in an ERK-dependent manner. 
Doulatov et al.

A

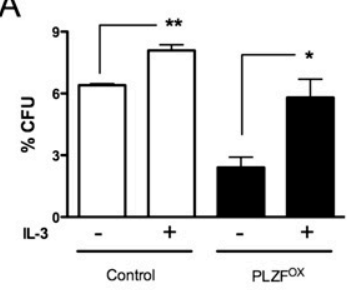

B

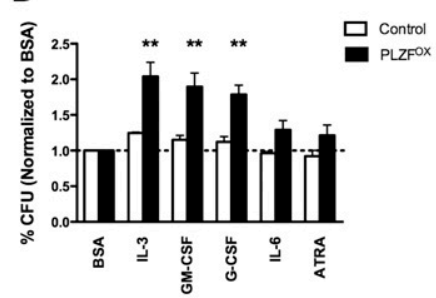

C

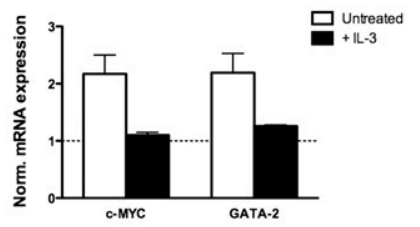

D

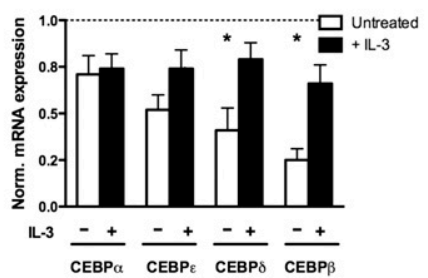

E

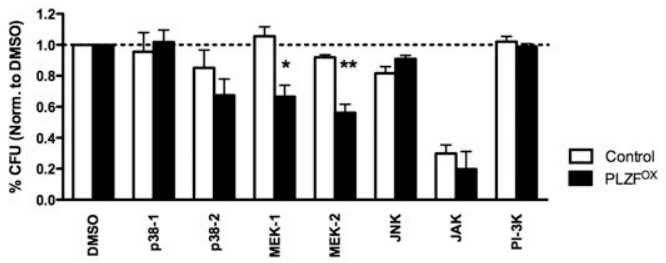

F

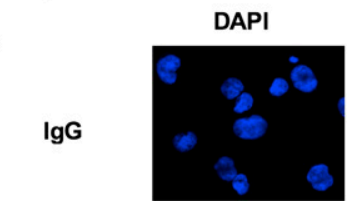

- IL-3
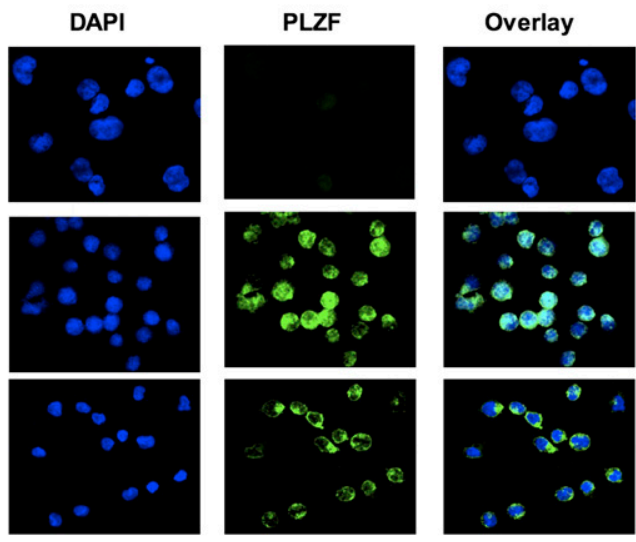

+ IL-3
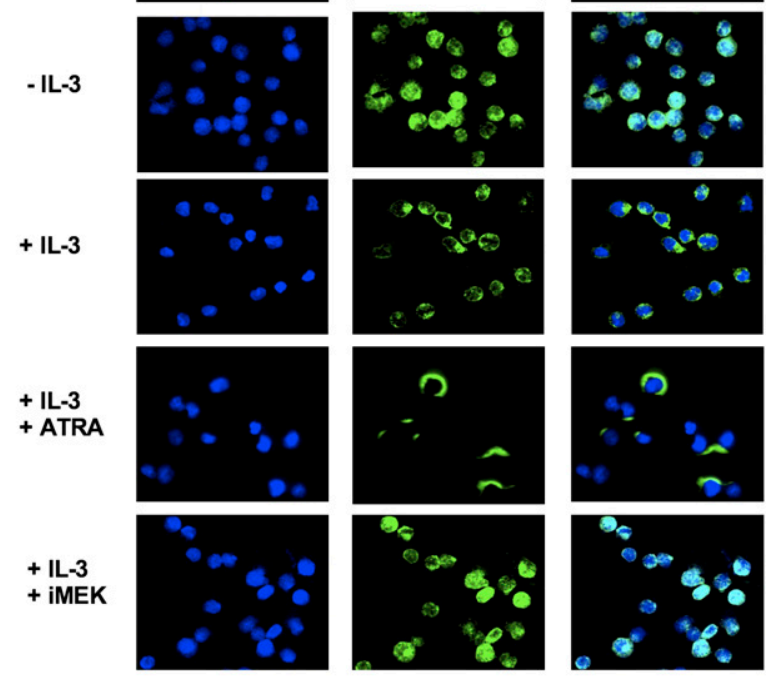

Figure 5. Cytokines modulate the effects of PLZF on growth and differentiation. $(A)$ Myeloid colony-forming capacity of CD34 ${ }^{+}$ $\mathrm{CD} 71^{-}$myeloid progenitors transduced with MPG (control) or MPG-PLZF (PLZF ${ }^{\mathrm{Ox}}$ ) viruses and seeded in methylcellulose \pm IL-3. (B) Same as $A$, except progenitors were stimulated with the indicated cytokines for $24 \mathrm{~h}$ in SFM + BIT and seeded in methylcellulose. Data were normalized to BSA-treated samples (dashed line). (C) Expression of MYC and GATA-2 in control or PLZF ${ }^{\mathrm{Ox}} \mathrm{CD}^{+} 4^{+} \mathrm{CD}^{-1}$ progenitors cultured for $4 \mathrm{~d}$ in serum-free media \pm IL-3. Expression is normalized to cells infected with a control virus (dashed line). (D) Same as $C$ for C/EBP transcription factors. Expression is normalized to cells infected with a control virus $\left(\right.$ dashed line). $\left({ }^{\star}\right) P<0.05$. $(E)$ Same as $A$, except progenitors were stimulated with IL-3 plus an indicated protein kinase inhibitor or DMSO vehicle for $24 \mathrm{~h}$ in SFM + BIT and seeded in methylcellulose. SB203580 inhibits p38-1, SB202190 inhibits p38-2, PD98059 inhibits MEK-1, U0126 inhibits MEK-2, SP600125 inhibits JNK, AG490 inhibits JAK, and LY294002 inhibits PI-3K. Data were normalized to DMSO-treated samples (dashed line). (F) Immunofluorescence staining of PLZF localization (green) in DAPI-stained nuclei or cytoplasm of nontransduced Lin ${ }^{-}$CD34 ${ }^{+}$ CD71- progenitors cultured in SFM + BIT \pm IL-3, ATRA, or PD98059 (iMEK) for $24 \mathrm{~h}$. Magnification, 100×. All data are expressed as mean \pm SEM of three independent experiments. $\left.\left(^{\star}\right) P<0.02 ;{ }^{\star \star \star}\right) P<0.006$.

\section{PLZF regulates expression of myeloid transcription factors}

To gain insight into the mechanisms that underlie the differentiation-suppressing function of PLZF, a genomewide analysis of PLZF promoter binding was performed using chromatin immunoprecipitation microarray (ChIP-chip) in KGla myeloid cells (K Rice, in prep.). The top candidates were then validated using conventional ChIP (Fig. 6A), and the transcriptional regulation of candidate targets was verified by qPCR in $\mathrm{Lin}^{-} \mathrm{CB}$. PLZF bound to promoters of transcription factors that control myeloid differentiation, including LEF1 (TCF1A) and GFI1 and repressed transcription, indicating that these are direct targets of PLZF (Fig. 6A,B). LEF1 is a nuclear cofactor of $\beta$-catenin, critical for lymphoid and myeloid development (Skokowa et al. 2006). GFI1 is a protooncogene that functions as a neutrophil lineage determinant downstream from $\mathrm{C} / \mathrm{EBP} \alpha$ (Laslo et al. 2006). Notably, PLZF also repressed CEBPA transcription but did not bind to its promoter, indicating indirect regulation (Fig. 6A,B).

Classically, PLZF has been regarded as a transcriptional repressor that recruits nuclear corepressor complexes to silence promoter activation (Hong et al. 1997). However, PLZF also bound to promoter sites of negative regulators of signaling and differentiation, including MYC, DUSP6, 

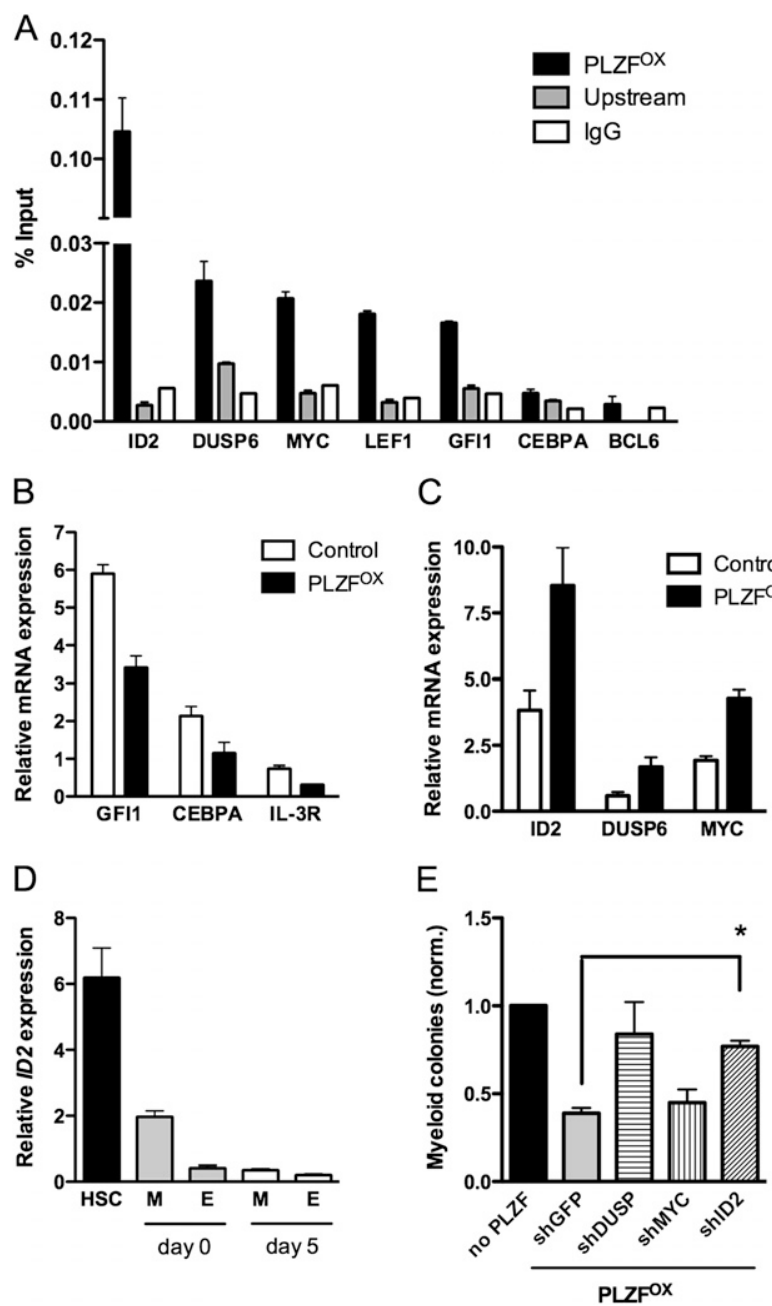

Figure 6. Transcriptional regulation of myeloid target genes by PLZF. (A) ChIP analysis of target promoter occupancy by PLZF in KG1a myeloid cells. ChIP was performed using an anti-PLZF antibody (PLZF) or control IgG (IgG). Binding is represented as fold enrichment over input determined by qPCR for promoter sequence containing consensus PLZF-binding sites, and an internal control sequence $6 \mathrm{~kb}$ upstream of transcriptional start site (Upstream). Binding to an intronic sequence of the BCL6 gene was used as a negative control. (B) Expression levels of GFI1, $C E B P A$, and $I L-3 R$ in control or $\mathrm{PLZF}^{\mathrm{OX}} \mathrm{CD} 34^{+} \mathrm{CD} 71^{-}$myeloid progenitors $24 \mathrm{~h}$ after transduction. $(C)$ Expression levels of $I D 2$, DUSP6, and MYC in control or PLZF ${ }^{\mathrm{OX}} \mathrm{CD} 34^{+} \mathrm{CD} 71^{-}$myeloid progenitors $24 \mathrm{~h}$ after transduction. (D) Expression levels of ID2 in human $\mathrm{CD} 34^{+} \mathrm{CD} 38^{-} \mathrm{HSCs}, \mathrm{CD} 34^{+} \mathrm{CD} 38^{+} \mathrm{CD} 71^{+}$erythroid $(\mathrm{E})$, and $\mathrm{CD} 34^{+} \mathrm{CD} 38^{+} \mathrm{CD} 71^{-}$myeloid $(\mathrm{M})$ progenitors sorted from fresh $\mathrm{Lin}^{-} \mathrm{CB}$ (day 0) or after $5 \mathrm{~d}$ culture in serum-free media (day 5). (E) Myeloid colony-forming capacity of CD34 ${ }^{+}$ $\mathrm{CD} 71^{-}$progenitors cotransduced with control or PLZF ${ }^{\mathrm{OX}}$ vectors and knockdown viruses for GFP, ID2, DUSP6, and MYC. All data are expressed as mean \pm SEM of three independent experiments, except $E$, which includes four experiments. $\left({ }^{\star}\right) P<0.005$.

and ID2, and activated their transcription (Fig. 6A,C). MYC is a proto-oncogene whose down-regulation is critical for myeloid differentiation (Johansen et al. 2001). DUSP6 is an ERK-specific phosphatase that acts as part of a negative feedback loop in FGF signaling ( $\mathrm{Li}$ et al. 2007). ID2 is a member of the basic helix-loop-helix (bHLH) transcription factor family and a negative regulator of differentiation (Ji et al. 2008). These data suggest that PLZF can recruit either corepressors or coactivators to target promoters to regulate gene expression.

Whereas $M Y C$ is expressed ubiquitously in hematopoiesis, expression of DUSP6 and ID2 is highest in HSCs and declines with differentiation (Fig. 6D; K Takenaka, in prep.). This observation suggests that DUSP6 and ID2 may act as cooperating factors downstream from PLZF. To test this hypothesis, CD $34^{+} \mathrm{CD} 71^{-}$myeloid progenitors were first transduced with the control (MPG) or $\mathrm{PLZF}^{\mathrm{OX}}$ vectors to induce ectopic PLZF expression. Cells were then cotransduced with shRNA vectors for PLZF target genes (MYC, ID2, and DUSP6) and plated in colony assays. Since each shRNA was introduced side-by-side into control and PLZF-overexpressing cells, any putative off-target effects would be equal in the presence or absence of ectopic PLZF. By normalizing the number of colonies formed by $\mathrm{PLZF}^{\mathrm{OX}}+$ shRNA-transduced progenitors to those transduced with MPG + shRNA, we selectively measured the effects of gene silencing that are specific to PLZF-overexpressing cells. PLZF ${ }^{\mathrm{OX}}$ myeloid progenitors transduced with shGFP or shMYC gave rise to fewer colonies compared with shGFP or shMYC alone (0.41 \pm 0.03 -fold and $0.46 \pm 0.06$-fold, respectively) indicating that PLZF retained its inhibitory effect on myeloid growth (Fig. 6E). However, shDUSP6 or shID2 restored the colony-forming potential of $\mathrm{PLZF}^{\mathrm{OX}}$ myeloid progenitors to $0.84 \pm 0.18$-fold and $0.78 \pm 0.03$-fold of the knockdown alone, although only the shID2 effect was significant $(P<0.005)$ (Fig. 6E). These data identify ID2 as a necessary downstream effector of the differentiationsuppressing function of PLZF.

\section{Discussion}

In this study, we present evidence that transcription factor networks that control hematopoietic specification also incorporate factors that inhibit normal differentiation, thereby playing an essential role in maintaining the steady-state output of mature cells and priming the system to be able to respond to conditions of immune activation. Although several transcription factors that suppress normal differentiation have been described, their biological role has remained unclear (Khanna-Gupta et al. 2001; Gery et al. 2004). In our model, the significance of this regulatory mechanism is readily apparent in PLZF-deficient cells, which generate increased numbers of mature progeny in a competitive transplant setting, but suffer from a depletion of the progenitor pool. Thus, the lack of negative regulation destines progenitors to eventual exhaustion as a result of excessive differentiation. At the other extreme, overexpression of PLZF is equally disruptive, shutting off the production of mature cells and causing a buildup of undifferentiated progenitors in vitro and in vivo. Thus, negative control of differentiation is essential for setting the balance between proliferation and differentiation, such that the loss of 
myeloid progenitors by differentiation is offset by their regeneration from primitive precursors including HSCs.

\section{Modulation of PLZF by stress-induced myeloid cytokines}

In addition to its role during homeostasis, negative control of proliferation and differentiation by PLZF is involved in priming the system for increased production of mature cells in response to cytokines. Cytokine stimulation induces progenitor cycling and causes a rapid differentiative response that depletes the progenitor pool (Hirai et al. 2006). Accordingly, sufficient numbers of progenitors must be made available in the event of emergencies; our data indicate that this is dependent on PLZF function. When the production of mature cells must be rapidly ramped up, this restriction on proliferation and differentiation is lifted via cytokine-induced signal transduction pathways, most notably p38 and ERK MAPKs. These pathways directly augment differentiation by activating positive regulators of differentiation, such as C/EBP $\beta$ and C/EBPE (Hu et al. 2001; Williamson et al. 2005). We show that activation of ERK by stressinduced cytokines, including IL-3, GM-CSF, and G-CSF, also interferes with PLZF-mediated repression of growth and differentiation. Thus, our data reveal greater complexity in the cytokine response, whereby the inactivation of anti-differentiation factors can function as a switch that shifts the balance in favor of differentiation.

Several protein modifications are required for full transcriptional activity of PLZF; notably, its acetylation by p300 (Guidez et al. 2005). The acetylated form localizes to discrete nuclear subdomains, while the deacetylated protein has a diffuse nuclear staining (Guidez et al. 2005). In another example, the proteolytic fragment of the heparinbinding epidermal growth factor inactivates PLZF by interacting with it in the nucleus and targeting it for export (Nanba et al. 2003). In both cases, its activation state is linked with altered cellular localization in the cytoplasm. Consistent with the previous reports (Reid et al. 1995), our data show that in CB-derived progenitors, PLZF is localized primarily in the nucleus. Following stimulation with IL-3, PLZF is redistributed to the cytoplasm, a localization that can be reversed by MEK inhibitors. This observation illustrates a potential mechanism by which cytokines interfere with PLZF function to quickly ramp up proliferation and differentiation. It remains to be shown whether active ERK inhibits PLZF directly targeting it for nuclear export, or if inhibition involves other factors. It was shown previously that activating FLT3 mutations antagonize PLZF by impairing its interaction with corepressors (Takahashi et al. 2004). A similar mechanism may be involved in PLZF inactivation by ERK, with reduced corepressor interaction targeting it for nuclear export.

\section{Molecular mechanisms of differentiation downstream from PLZF}

Our evidence indicates that PLZF shifts the balance against differentiation by concertedly repressing expression of myeloid transcription factors GFI1, LEF1, and C/
$\mathrm{EBP} \alpha$, and activating MYC and ID2. Normal granulocytic differentiation is orchestrated by the C/EBP $\alpha-G F I 1$ regulatory circuit (Hock et al. 2003; Laslo et al. 2006). Consistent with this, our results showed that granulocyte numbers were most significantly increased in mice transplanted with PLZF-deficient cells, compared with other lineages. Interestingly, mutations in GFI1 and the loss of LEF1 expression are associated with severe congenital neutropenia, a disorder marked by susceptibility to opportunistic infections due to low neutrophil counts (Person et al. 2003; Skokowa et al. 2006). Our study therefore provides the rationale to investigate the role of PLZF in this disorder.

ID2 may establish a molecular state refractory to differentiation by repressing tissue-specific transcription factors, such as E2A and SCL (Lasorella et al. 2001). In hematopoiesis, ID2 functions as a negative regulator of B-lymphoid and myeloid commitment owing to its interaction with E2A and PU.1 (Ji et al. 2008). We demonstrated that ID2 mRNA is expressed at the highest levels in HSCs and declines in progenitors. Furthermore, our results establish that PLZF up-regulates ID2 expression in myeloid progenitors and that ID2 is required to maintain the repressive effect of PLZF on differentiation. Thus, a major mechanism by which PLZF regulates myeloid development is by inducing ectopic ID2 expression, which antagonizes other lineage-specific transcription factors.

In conclusion, our findings point to a central role of differentiation-suppressing mechanisms in establishing developmental homeostasis by regulating the balance between the progenitor pool and the production of mature cells. More broadly, our study demonstrates the practicality of taking a genetic approach to unraveling the developmental program in primary human hematopoietic cells. Such an approach is important, as surrogate models may not entirely recapitulate the intrinsic complexity of the human developmental processes.

\section{Materials and methods}

\section{Sample collection and purification}

$\mathrm{CB}$ samples were obtained according to procedures approved by the institutional review boards of the University Health Network and Trillium Hospital, and were collected, processed, and stored as described (Mazurier et al. 2004). Briefly, Lin ${ }^{-}$CB cells were purified by negative selection using the StemSep Human Progenitor Cell Enrichment Kit according to the manufacturer's protocol (StemCell Technologies).

\section{Viral constructs}

Full-length $P L Z F$ cDNA was cloned into a two-promoter MSCVPGK-EGFP (MPG) retroviral vector and a cppt-PGK-EGFPWPRE-derived lentiviral vector (Mazurier et al. 2004) with a truncated E1F $\alpha$ promoter. shRNAs against PLZF were designed using the Dharmacon algorithm (Dharmacon, Inc.; see the Supplemental Material for sequences), synthesized as complimentary $5^{\prime}$-P oligonucleotides, annealed, and cloned into the modified cppt-PGK-EGFP-WPRE vector containing the H1 promoter 
and an ires-PAC selection cassette. Viral particles pseudotyped with VSV-G were generated by transient transfection as described (Mazurier et al. 2004).

\section{Viral transduction}

Lin $^{-}$CB cells were prestimulated and transduced in X-VIVO 10 (BioWhittaker) medium with $1 \%$ BSA, $2 \mathrm{mM}$ L-glutamine, 100 $\mathrm{U} / \mathrm{mL}$ penicillin-streptomycin, plus SCF (100 ng/mL), FLT3L (100 ng/mL), TPO (50 ng/mL), and IL-6 (20 ng/mL) (all Amgen) for $4 \mathrm{~h}$ (lenti) or $24 \mathrm{~h}$ (retro). For lentiviral infections, cells were transduced at multiplicity of infection (MOI) 50-100 for $24 \mathrm{~h}$. For retroviral infections, $\sim 1 \times 10^{6}$ cells were transduced with four changes of $1 \times 10^{7}$ to $5 \times 10^{7}$ viral particles each for $48 \mathrm{~h}$; wells were precoated with CH-296 fibronectin $\left(4 \mu \mathrm{g} / \mathrm{cm}^{2}\right.$; Retronectin, Takara Bio, Inc.).

\section{Cell sorting}

Retrovirus-transduced cells were cultured in transduction medium for $24 \mathrm{~h}$ after gene transfer. Cells were stained with antibodies against CD34 and CD71 (BD Pharmingen). GFP ${ }^{+}$ $\mathrm{CD} 4^{+}\left(\mathrm{CD}_{71^{-}}\right)$progenitors were sorted on BD FACSAria cytometer operating in the "Purity" mode, consistently yielding $>98 \%$ purity.

\section{Flow cytometry}

Routine flow cytometry was performed using BD FACSCalibur or BD LSRII cytometers on fresh cells using monoclonal mouse anti-human antibodies (see the Supplemental Material). Data were analyzed with FlowJo software (Tree Star, Inc.).

\section{Liquid cultures}

Sorted cells $\left(2 \times 10^{4}\right.$ to $\left.5 \times 10^{4}\right)$ were seeded into $1 \mathrm{~mL} \mathrm{IMDM} \mathrm{+}$ $15 \%$ FCS plus SCF $(20 \mathrm{ng} / \mathrm{mL})$ and IL-3 $(2 \mathrm{ng} / \mathrm{mL})$ or IMDM + $20 \%$ BIT (StemCell Technologies), $2 \mathrm{mM}$ L-glutamine, 0.1 $\mathrm{mM}$-mercaptoethanol, plus SCF (100 ng/mL), FLT3L (100 $\mathrm{ng} / \mathrm{mL}), \mathrm{IL}-6(20 \mathrm{ng} / \mathrm{mL}), \mathrm{G}-\mathrm{CSF}(20 \mathrm{ng} / \mathrm{mL})$, and GM-CSF (20 $\mathrm{ng} / \mathrm{mL}$ ) (all cytokines; Amgen). Cultures were maintained at a density of $\sim 1 \times 10^{6}$ cells per milliliter and $1 \times 10^{5}$ cells were used for analysis of lineage markers with antibodies against CD11b, CD14, and CD15 (Beckman Coulter), and CD33 (BD Pharmingen).

\section{Colony assays}

Sorted progenitors $\left(1 \times 10^{3}\right)$ were seeded into $3 \mathrm{~mL}$ of MethoCult medium (StemCell Technologies) with 20\% FCS, 5\% human plasma, $5 \%$ CB plasma, $0.1 \mathrm{mM} \beta$-mercaptoethanol, plus "basic" cytokines SCF (10 ng/mL), FLT3L (10 ng/mL), TPO (50 ng/mL), IL-6 (10 ng/mL), GM-CSF $(50 \mathrm{ng} / \mathrm{mL})$, and EPO $(4 \mathrm{U} / \mathrm{mL})$. Duplicate 1-mL aliquots were plated into $35-\mathrm{mm}$ dishes (Nunc) and hematopoietic colonies of erythroid, myeloid, or mixed lineage were scored after $14 \mathrm{~d}$.

\section{BrdU and annexin assays}

BrdU was added to day 7 liquid cultures at $10 \mu \mathrm{M}$ final concentration. After $3 \mathrm{~h}$ of incubation, $1 \times 10^{5}$ cells were removed, stained with anti-CD11b-PE (Beckman Coulter), and assayed with BrdU Flow Kit and Annexin V-PE Apoptosis Detection Kit (both BD Pharmingen) according to the manufacturer's protocols.

\section{NOD/SCID transplantation}

NOD_LtSz-scid_scid (NOD/SCID) mice were sublethally irradiated (300 cGy) and injected i.p. with $200 \mu \mathrm{g}$ of anti-CD122 monoclonal antibody $24 \mathrm{~h}$ prior to transplantation (McKenzie et al. 2005). Transduced cells were washed, resuspended at $7.5 \times$ $10^{4}$ cells in $20 \mu \mathrm{L}$ of PBS $+1 \%$ FCS, and injected intrafemorally into anesthetized mice. Mice were sacrificed after $8 \mathrm{wk}$, BMCs were isolated by flushing with $2 \mathrm{~mL}$ of IMDM, and $50 \mu \mathrm{L}$ were stained for surface markers (see the Supplemental Material for antibodies). Remaining cells were pooled from all mice within a group $(n=4-8)$, red blood cell lysed, and used for surface antigen staining and lineage-depletion (see below).

\section{Lineage depletion}

Human progenitors were isolated from pooled bone marrow using the Mouse/Human Chimera Enrichment Kit (StemCell Technologies) according to the manufacturer's protocol, with the addition of $100 \mu \mathrm{L} / \mathrm{mL}$ StemSep Human Hematopoietic Progenitor Enrichment Cocktail (StemCell Technologies) and the anti-biotin antibody. Fresh column-purified cells were used for flow cytometry and seeded in colony assays at $1 \times 10^{3}$ cells per plate, and $\mathrm{GFP}^{+}$colonies were scored using an inverted fluorescent microscope.

\section{Cytokine stimulation}

Sorted $\mathrm{GFP}^{+} \mathrm{CD} 34^{+} \mathrm{CD} 71^{-}$progenitors were either directly seeded into methylcellulose with basic cytokines, without EPO, $\pm 50 \mathrm{ng} / \mathrm{mL} \mathrm{IL-3}$, or $1 \times 10^{4}$ cells were stimulated in $\mathrm{IMDM}+20 \% \mathrm{BIT}+2 \mathrm{mM}$ L-glutamine $\pm 20 \mathrm{ng} / \mathrm{mL}$ IL-3, G-CSF, GM-CSF, IL-6, or $10^{-7}$ M ATRA (Sigma Aldrich) for $24 \mathrm{~h}$, after which $1.5 \times 10^{3}$ cells were seeded into methylcellulose with basic cytokines. For inhibitor studies, cells were stimulated as above with the addition of $10 \mu \mathrm{M}$ SB203580, $50 \mu \mathrm{M}$ SB202190, $10 \mu \mathrm{M}$ PD98059, $10 \mu \mathrm{M}$ U0126, $25 \mu \mathrm{M}$ SP600125, $25 \mu \mathrm{M}$ AG490, $50 \mu$ M LY294002, or DMSO vehicle (all Tocris Bioscience). All inhibitors were used at previously determined concentrations (see the Supplemental Material for references).

\section{Immunofluorescence microscopy}

Nontransduced CD34 ${ }^{+} \mathrm{CD}^{-} 1^{-}$progenitors were cultured in IMDM $+20 \%$ BIT $+2 \mathrm{mM}$ L-glutamine $\pm 50 \mathrm{ng} / \mathrm{mL} \mathrm{IL-3,}$ $10^{-7} \mathrm{M}$ ATRA or $10 \mu \mathrm{M}$ PD98059 for $24 \mathrm{~h}$. Cells were fixed in $2 \%$ paraformaldehyde and $5 \times 10^{4}$ cells were cytospun onto microscope slides. See the Supplemental Material for a complete staining protocol.

\section{Quantitative RT-PCR}

More than $5 \times 10^{4}$ sorted $\mathrm{GFP}^{+} \mathrm{CD} 34^{+} \mathrm{CD} 71^{-}$progenitors were cultured in IMDM $+20 \%$ BIT $+2 \mathrm{mM} \mathrm{L}$-glutamine $\pm 20 \mathrm{ng} / \mathrm{mL}$ IL-3 for $24 \mathrm{~h}$. RNA was extracted with the Trizol reagent (Invitrogen), DNase I-treated (Qiagen), and reverse-transcribed using SuperScript II (Invitrogen). Real-time PCR reactions were prepared using SYBR Green PCR Master Mix (Applied Biosystems), with $200 \mathrm{nM}$ each primer and $>20 \mathrm{ng}$ of cDNA per reaction (all $60^{\circ} \mathrm{C}$ annealing $\mathrm{T}$; see the Supplemental Material for the primer list). Reactions were performed in triplicate on Applied Biosystems 7900HT instruments. Absolute gene expression was quantified using SDS software (Applied Biosystems) based on the standard curve method and presented as transcript expression (picograms)/GAPDH (picograms) × 100 . 
ChIP

See the Supplemental Material for the complete protocol.

\section{Statistical analysis}

Unless otherwise stated, significance of differences among groups was determined by two-tailed unpaired Student's $t$-test. Standard errors of the products or norms of two independent data sets were calculated using the MSTAT software (McArdle Laboratory for Cancer Research).

\section{Acknowledgments}

We thank J.E.D. laboratory members for critical reading and discussion of the manuscript, UHN/SickKids Flow Cytometry Facility staff (P. Pentilla and S. Zhao) for flow cytometry assistance, and Jason Moffat (University of Toronto) for providing lentiviral shRNA vectors. This work was supported by a Canadian Institute of Health Research (CIHR)-University of Toronto Collaborative Graduate Training Program in Molecular Medicine studentship (to S.D.), s CIHR Doctoral Research award (to F.N.), grants from the CIHR and the Ontario Institute for Cancer Research, and a Summit Award both with funds from the Province of Ontario, Genome Canada through the Ontario Genomics Institute, a Canada Research Chair, the Leukemia and Lymphoma Society, the Canadian Cancer Society, and the Terry Fox Foundation (to J.E.D.). J.D.L and A.Z. were sponsored by NIH grant CA 59936-JDL.

\section{References}

Barna M, Hawe N, Niswander L, Pandolfi PP. 2000. Plzf regulates limb and axial skeletal patterning. Nat Genet 25: 166-172.

Barna M, Merghoub T, Costoya JA, Ruggero D, Branford M, Bergia A, Samori B, Pandolfi PP. 2002. Plzf mediates transcriptional repression of HoxD gene expression through chromatin remodeling. Dev Cell 3: 499-510.

Barreda DR, Hanington PC, Belosevic M. 2004. Regulation of myeloid development and function by colony stimulating factors. Dev Comp Immunol 28: 509-554.

Bjerregaard MD, Jurlander J, Klausen P, Borregaard N, Cowland JB. 2003. The in vivo profile of transcription factors during neutrophil differentiation in human bone marrow. Blood 101: 4322-4332.

Buaas FW, Kirsh AL, Sharma M, McLean DJ, Morris JL, Griswold MD, de Rooij DG, Braun RE. 2004. Plzf is required in adult male germ cells for stem cell self-renewal. Nat Genet 36: 647-652.

Cannistra SA, Griffin JD. 1988. Regulation of the production and function of granulocytes and monocytes. Semin Hematol 25: 173-188.

Chen Z, Brand NJ, Chen A, Chen SJ, Tong JH, Wang ZY, Waxman S, Zelent A. 1993. Fusion between a novel Kruppel-like zinc finger gene and the retinoic acid receptor- $\alpha$ locus due to a variant $\mathrm{t}(11 ; 17)$ translocation associated with acute promyelocytic leukaemia. EMBO J 12: 1161-1167.

Costoya JA, Hobbs RM, Barna M, Cattoretti G, Manova K, Sukhwani M, Orwig KE, Wolgemuth DJ, Pandolfi PP. 2004. Essential role of Plzf in maintenance of spermatogonial stem cells. Nat Genet 36: 653-659.

Donahue RE, Seehra J, Metzger M, Lefebvre D, Rock B, Carbone S, Nathan DG, Garnick M, Sehgal PK, Laston D, et al. 1988. Human IL-3 and GM-CSF act synergistically in stimulating hematopoiesis in primates. Science 241: 1820-1823.
Fisher AG. 2002. Cellular identity and lineage choice. Nat Rev Immunol 2: 977-982.

Gery S, Park DJ, Vuong PT, Chih DY, Lemp N, Koeffler HP. 2004. Retinoic acid regulates C/EBP homologous protein expression (CHOP), which negatively regulates myeloid target genes. Blood 104: 3911-3917.

Guidez F, Howell L, Isalan M, Cebrat M, Alani RM, Ivins S, Hormaeche I, McConnell MJ, Pierce S, Cole PA, et al. 2005. Histone acetyltransferase activity of p300 is required for transcriptional repression by the promyelocytic leukemia zinc finger protein. Mol Cell Biol 25: 5552-5566.

Hirai H, Zhang P, Dayaram T, Hetherington CJ, Mizuno S, Imanishi J, Akashi K, Tenen DG. 2006. C/EBP $\beta$ is required for 'emergency' granulopoiesis. Nat Immunol 7: 732-739.

Hock H, Hamblen MJ, Rooke HM, Traver D, Bronson RT, Cameron S, Orkin SH. 2003. Intrinsic requirement for zinc finger transcription factor Gfi-1 in neutrophil differentiation. Immunity 18: 109-120.

Hong SH, David G, Wong CW, Dejean A, Privalsky ML. 1997. SMRT corepressor interacts with PLZF and with the PMLretinoic acid receptor $\alpha(\mathrm{RAR} \alpha)$ and PLZF-RAR $\alpha$ oncoproteins associated with acute promyelocytic leukemia. Proc Natl Acad Sci 94: 9028-9033.

Hu J, Roy SK, Shapiro PS, Rodig SR, Reddy SP, Platanias LC, Schreiber RD, Kalvakolanu DV. 2001. ERK1 and ERK2 activate CCAAAT/enhancer-binding protein- $\beta$-dependent gene transcription in response to interferon- $\gamma$. J Biol Chem 276: 287-297.

Ji M, Li H, Suh HC, Klarmann KD, Yokota Y, Keller JR. 2008. Id2 intrinsically regulates lymphoid and erythroid development via interaction with different target proteins. Blood 112: 1068-1077.

Johansen LM, Iwama A, Lodie TA, Sasaki K, Felsher DW, Golub TR, Tenen DG. 2001. c-Myc is a critical target for c/EBP $\alpha$ in granulopoiesis. Mol Cell Biol 21: 3789-3806.

Khanna-Gupta A, Zibello T, Sun H, Lekstrom-Himes J, Berliner N. 2001. C/EBP $\varepsilon$ mediates myeloid differentiation and is regulated by the CCAAT displacement protein $(\mathrm{CDP} /$ cut $)$. Proc Natl Acad Sci 98: 8000-8005.

Kobayashi-Osaki M, Ohneda O, Suzuki N, Minegishi N, Yokomizo T, Takahashi S, Lim KC, Engel JD, Yamamoto M. 2005. GATA motifs regulate early hematopoietic lineage-specific expression of the Gata2 gene. Mol Cell Biol 25: 7005-7020.

Kovalovsky D, Uche OU, Eladad S, Hobbs RM, Yi W, Alonzo E, Chua K, Eidson M, Kim HJ, Im JS, et al. 2008. The BTB-zinc finger transcriptional regulator PLZF controls the development of invariant natural killer T cell effector functions. Nat Immunol 9: 1055-1064.

Labbaye C, Spinello I, Quaranta MT, Pelosi E, Pasquini L, Petrucci E, Biffoni M, Nuzzolo ER, Billi M, Foa R, et al. 2008. A three-step pathway comprising PLZF/miR-146a/ CXCR4 controls megakaryopoiesis. Nat Cell Biol 10: 788801.

Laiosa CV, Stadtfeld M, Graf T. 2006. Determinants of lymphoidmyeloid lineage diversification. Annu Rev Immunol 24: 705738.

Laslo P, Spooner CJ, Warmflash A, Lancki DW, Lee HJ, Sciammas R, Gantner BN, Dinner AR, Singh H. 2006. Multilineage transcriptional priming and determination of alternate hematopoietic cell fates. Cell 126: 755-766.

Lasorella A, Uo T, Iavarone A. 2001. Id proteins at the cross-road of development and cancer. Oncogene 20: 8326-8333.

Li C, Scott DA, Hatch E, Tian X, Mansour SL. 2007. Dusp6 (Mkp3) is a negative feedback regulator of FGF-stimulated ERK signaling during mouse development. Development 134: $167-176$. 
Lieschke GJ, Grail D, Hodgson G, Metcalf D, Stanley E, Cheers C, Fowler KJ, Basu S, Zhan YF, Dunn AR. 1994. Mice lacking granulocyte colony-stimulating factor have chronic neutropenia, granulocyte and macrophage progenitor cell deficiency, and impaired neutrophil mobilization. Blood 84: $1737-1746$.

Mazurier F, Gan O, McKenzie J, Doedens M, Dick J. 2004. Lentivector-mediated clonal tracking reveals intrinsic heterogeneity in the human hematopoietic stem cell compartment and culture-induced stem cell impairment. Blood 103: 545-552.

McConnell MJ, Chevallier N, Berkofsky-Fessler W, Giltnane JM, Malani RB, Staudt LM, Licht JD. 2003. Growth suppression by acute promyelocytic leukemia-associated protein PLZF is mediated by repression of c-myc expression. Mol Cell Biol 23: 9375-9388.

McKenzie JL, Gan OI, Doedens M, Dick JE. 2005. Human shortterm repopulating stem cells are efficiently detected following intrafemoral transplantation into NOD/SCID recipients depleted of CD122 $2^{+}$cells. Blood 106: 1259-1261.

Nanba D, Mammoto A, Hashimoto K, Higashiyama S. 2003. Proteolytic release of the carboxy-terminal fragment of proHB-EGF causes nuclear export of PLZF. J Cell Biol 163: 489-502.

Oster W, Lindemann A, Mertelsmann R, Herrmann F. 1988. Regulation of gene expression of M-, G-, GM-, and multi-CSF in normal and malignant hematopoietic cells. Blood Cells 14: 443-462.

Panopoulos AD, Zhang L, Snow JW, Jones DM, Smith AM, El Kasmi KC, Liu F, Goldsmith MA, Link DC, Murray PJ, et al. 2006. STAT3 governs distinct pathways in emergency granulopoiesis and mature neutrophils. Blood 108: 3682-3690.

Person RE, Li FQ, Duan Z, Benson KF, Wechsler J, Papadaki HA, Eliopoulos G, Kaufman C, Bertolone SJ, Nakamoto B, et al. 2003. Mutations in proto-oncogene GFI1 cause human neutropenia and target ELA2. Nat Genet 34: 308-312.

Reid A, Gould A, Brand N, Cook M, Strutt P, Li J, Licht J, Waxman S, Krumlauf R, Zelent A. 1995. Leukemia translocation gene, PLZF, is expressed with a speckled nuclear pattern in early hematopoietic progenitors. Blood 86: 45444552.

Rosenbauer F, Tenen DG 2007. Transcription factors in myeloid development: Balancing differentiation with transformation. Nat Rev Immunol 7: 105-117.

Savage AK, Constantinides MG, Han J, Picard D, Martin E, Li B, Lantz O, Bendelac A. 2008. The transcription factor PLZF directs the effector program of the NKT cell lineage. Immunity 29: 391-403.

Shaknovich R, Yeyati PL, Ivins S, Melnick A, Lempert C, Waxman S, Zelent A, Licht JD. 1998. The promyelocytic leukemia zinc finger protein affects myeloid cell growth, differentiation, and apoptosis. Mol Cell Biol 18: 5533-5545.

Skokowa J, Cario G, Uenalan M, Schambach A, Germeshausen M, Battmer K, Zeidler C, Lehmann U, Eder M, Baum C, et al. 2006. LEF-1 is crucial for neutrophil granulocytopoiesis and its expression is severely reduced in congenital neutropenia. Nat Med 12: 1191-1197.

Takahashi S, McConnell MJ, Harigae H, Kaku M, Sasaki T, Melnick AM, Licht JD. 2004. The Flt3 internal tandem duplication mutant inhibits the function of transcriptional repressors by blocking interactions with SMRT. Blood 103: 4650-4658.

Ward JO, McConnell MJ, Carlile GW, Pandolfi PP, Licht JD, Freedman LP. 2001. The acute promyelocytic leukemiaassociated protein, promyelocytic leukemia zinc finger, regulates 1,25-dihydroxyvitamin $\mathrm{D}(3)$-induced monocytic differentiation of U937 cells through a physical interaction with vitamin $\mathrm{D}(3)$ receptor. Blood 98: 3290-3300.

Williamson EA, Williamson IK, Chumakov AM, Friedman AD, Koeffler HP. 2005. CCAAT/enhancer binding protein $\varepsilon$ : Changes in function upon phosphorylation by p38 MAP kinase. Blood 105: 3841-3847. 


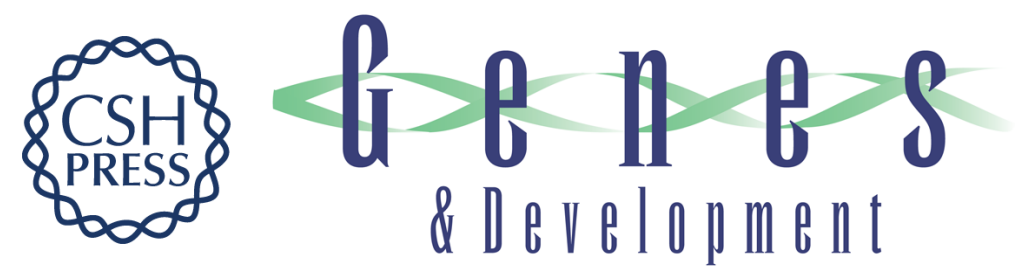

\section{PLZF is a regulator of homeostatic and cytokine-induced myeloid development}

Sergei Doulatov, Faiyaz Notta, Kim L. Rice, et al.

Genes Dev. 2009, 23:

Access the most recent version at doi:10.1101/gad.1788109

Supplemental http://genesdev.cshlp.org/content/suppl/2009/08/14/23.17.2076.DC1
Material

References This article cites 42 articles, 22 of which can be accessed free at:

http://genesdev.cshlp.org/content/23/17/2076.full.html\#ref-list-1

License

Email Alerting

Receive free email alerts when new articles cite this article - sign up in the box at the top

Service

right corner of the article or click here.

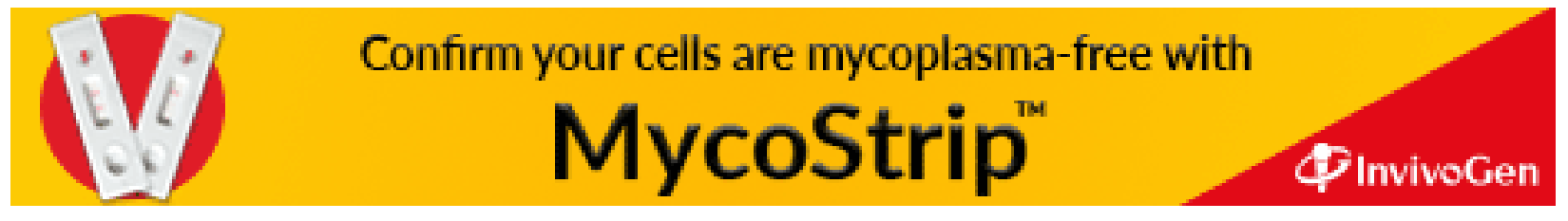

